\title{
RANCIDEZ HIDROLÍTICA E OXIDATIVA EM QUEIJOS DA SERRA GAÚCHA E SUA RELAÇÃO COM PARÂMETROS NUTRICIONAIS E MICROBIOLÓGICOS ${ }^{1}$
}

\author{
HYDROLYTIC AND OXIDATIVE RANCIDITY IN CHEESE OF SERRA GAUCHA \\ AND ITS RELATION TO NUTRITIONAL AND MICROBIOLOGICAL PARAMETERS
}

\author{
Marli Velho Menegol ${ }^{2 *}$, Sandra Dornelles ${ }^{3 *}$, Fabiane Bairros ${ }^{4}$, \\ Catia Santos Branco 5 e Elizete Maria Pesamosca Facco ${ }^{6 *}$
}

\section{RESUMO}

O queijo artesanal serrano é produzido a partir de leite não pasteurizado, o qual é o responsável pelas suas características organolépticas, bem como sua susceptibilidade à degradação. $\mathrm{O}$ objetivo do presente estudo foi avaliar parâmetros físico-químicos e microbiológicos e correlacionar com rancidez hidrolítica e oxidativa em queijos artesanais produzidos na Serra Gaúcha ( $\mathrm{n}=25)$, maturados em diferentes tempos ( 0 a 10 dias; 20 a 30 dias; 45 a 60 dias). O teor de umidade, minerais totais (cinzas), sódio ( $\mathrm{Na}$ ) e lipídeos, ocorrência de rancidez hidrolítica e oxidativa e a presença de microrganismos (Coliformes termotolerantes, Estafilococos coagulase positiva, Salmonella sp. e Listeria monocytogenes) foram analisados. Observou-se diferença estatística entre o conteúdo de umidade e lipídeos, mostrando níveis maiores desses nas amostras mais imaturas $(\mathrm{p}<0.05)$. Com relação ao teor de sódio e minerais não houve diferença estatística significativa. Na análise microbiológica detectou-se a presença de coliformes termotolerantes e Estafilococos em níveis superiores a $10^{6} \mathrm{UFC} / \mathrm{g}$ em 100 $\%$ das amostras, independentemente do tempo de maturação. Esses achados foram acompanhados por níveis aumentados de rancificação hidrolítica e oxidativa de forma tempo-dependente. Os dados aqui encontrados contribuirão para o melhor entendimento sobre as causas e consequências das alterações físico-químicas e microbiológicas que podem ocorrer no queijo artesanal serrano e quais seus impactos nutricionais.

Palavras-chave: Laticínios, Segurança alimentar e nutricional, Substâncias reativas ao ácido tiobarbitúrico.

\section{ABSTRACT}

Serrano artisanal cheese is made from unpasteurized milk, which is responsible for its organoleptic characteristics, as well as its susceptibility to degradation. The objective of the present study was to evaluate the physicochemical and microbiological parameters and to correlate with hydrolytic and oxidative rancidity in artisanal cheeses produced in Serra Gaúcha (n=25), matured at different times (0-10 days, 20-30, 45-60 days). The content of moisture, total minerals (ash), sodium ( $\mathrm{Na}$ ) and lipids, occurrence of hydrolytic and oxidative rancidity and the presence of microorganisms (Coliformes termotolerantes, Coagulase positive Estafilococos, Salmonella sp. and Listeria monocytogenes) were analyzed. Statistical differences were 1 Artigo científico.

*Esses autores contribuíram igualmente para este artigo.

2 Acadêmica do Curso de Nutrição - Universidade de Caxias do Sul - UCS. E-mail: mvmenego@ucs.br

3 Acadêmica do Curso de Farmácia - Universidade de Caxias do Sul - UCS. E-mail: sjdornel@ucs.br 4 Acadêmica do Curso de Química - Universidade de Caxias do Sul - UCS. E-mail: frbairros@ucs.br 5 Colaborador. Docente da Área do Conhecimento de Ciências da Vida. Laboratório de Estresse Oxidativo e Antioxidantes, Instituto de Biotecnologia - Universidade de Caxias do Sul - UCS. E-mail: csbranc1@ucs.br 6 Orientador. Docente da Área do Conhecimento de Ciências da Vida. Laboratório de Bromatologia e de Microbiologia de Alimentos - Universidade de Caxias do Sul - UCS. E-mail: empfacco@ucs.br 
observed between moisture and lipids, showing higher levels in immature samples $(p<0.05)$. Regarding the sodium and mineral content, no significant statistical difference was found. In the microbiological analysis, the presence of thermotolerant coliforms and Coagulase positive Staphylococcus higher than $106 \mathrm{CFU} / \mathrm{g}$ were detected in $100 \%$ of the samples, regardless of maturation time. These findings were accompanied by increased levels of hydrolytic and oxidative rancidity in a time-dependent manner. These data will contribute to a better understanding of the causes and consequences for physicochemical and microbiological alterations that can occur in artisanal cheese and its nutritional impacts.

Keywords: Dairy Products, Food and nutrition security, Thiobarbituric Acid Reactive Substances.

\section{INTRODUÇÃO}

Os queijos produzidos a partir do leite bovino oferecem uma variedade de tipos, sabores e texturas (ABIQ, 2019). Entre esses queijos destacam-se os artesanais, como o queijo Serrano, que é um alimento com sabor e aromas acentuados com cor que pode variar do amarelo ao amarelo-palha, possuir consistência elástica tendendo a untuosidade, podendo apresentar olhaduras ou não e uma crosta de média espessura, lisa e sem trincas, sendo que todas essas particularidades são destacadas com o processo de maturação (PEREIRA et al., 2014; SANTA CATARINA, 2017; ABIQ, 2019).

O queijo Serrano serve não só para consumo na alimentação das famílias, mas como um gerador de renda extra para custeio das despesas dos pequenos produtores. Sua comercialização é feita diretamente ao consumidor em carros na beira da estrada, em tendas, mercearias e nas propriedades (ZAFFARI et al., 2007). O produto é muito apreciado e apresenta características sensoriais que o valorizam, além de ser fonte de macro e micronutrientes. Por se tratar de um produto artesanal, sua composição não consta em tabelas de composição de alimentos, no entanto apresenta características similares ao queijo minas meia cura (TACO, 2011).

A produção do queijo Serrano deve ser iniciada em até uma hora após o final da ordenha sem a pasteurização do leite, sendo que a ordenha deve ser de forma manual ou mecânica. Além de ser produzido dessa forma, para ser considerado o verdadeiro queijo Serrano, este deve ser produzido em cidades delimitadas da região da Serra Gaúcha ou Catarinense (RIO GRANDE DO SUL, 2016; SANTA CATARINA, 2017).

Com o passar do tempo houve alterações no processo de produção do queijo, como a substituição do coalho animal pelo industrial e o tempo de maturação, que de acordo com a legislação vigente é de no mínimo 60 dias (SANTA CATARINA, 2017). No entanto, uma redução nesse período pode ser avaliada a partir de estudos técnico-sanitários que comprovem cientificamente a manutenção da qualidade e a inocuidade do produto (CRUZ E MENASHE, 2014; FREITAS, 2015; SANTA CATARINA, 2017).

Com relação aos parâmetros microbiológicos, alguns queijos coloniais podem conter microrganismos além do que as normas de segurança preconizam, podendo levar o consumidor a intoxicações 
e infecções. O não cumprimento das exigências sanitárias legais aumenta os riscos de contaminação por esses agentes, dentre os mais comuns estão enterobactérias, fungos e leveduras. O estufamento dos queijos, consequência da produção de gás e expansão dos mesmos, está associado à contaminação por bactéria do grupo coliforme, principalmente, comprometendo o sabor e a aparência do produto, indicando deficiência sanitária (SOBRAL et al., 2017).

Outro problema relacionado à estabilidade dos queijos é a sua propensão à rancificação, devido ao alto conteúdo de lipídeos e água em sua composição. A degradação da gordura durante a produção de queijos pode causar rancidez hidrolítica e/ou oxidativa provocando um sabor indesejado (ZAFFARI et al., 2007; SOBRAL et al., 2017).

Com base nos aspectos citados, é importante avaliar a estabilidade físico-química e microbiológica dos queijos artesanais Serranos, os quais são fonte importante de macro e micronutrientes para a população.

\section{MATERIAL E MÉTODOS}

Trata-se de um estudo experimental em análise de alimentos. Foram coletadas aleatoriamente amostras de queijo Serrano produzidos de forma artesanal de diferentes produtores dos municípios de Cambará do Sul e São Francisco de Paula no período de abril à junho de 2019. As amostras (n=25) foram adquiridas em diferentes períodos de maturação, sendo 0 a 10 dias (categoria 1); 20 a 30 dias (categoria 2) e 45 a 60 dias (categoria 3), estando armazenadas à temperatura ambiente (média de $19 \pm 8{ }^{\circ} \mathrm{C}$ no período) e não embaladas. As amostras permaneceram no local de aquisição até as análises para que a temperatura, a luz e a umidade não alterassem os resultados. O transporte das amostras foi feito em caixas isotérmicas, afim de que as características físico-químicas e microbiológicas do produto não fossem modificadas.

As análises químicas foram realizadas no Laboratório de Bromatologia e de Microbiologia de Alimentos da Universidade de Caxias do Sul. Para os ensaios, as mesmas foram trituradas, homogeneizadas e analisadas quanto aos parâmetros de umidade, conteúdo de minerais totais (cinzas) e sódio (Na), teor lipídico, parâmetros microbiológicos e índice de rancidez (oxidativa e hidrolítica). Cada ensaio foi realizado em triplicata e os resultados foram expressos em porcentagem.

A umidade foi analisada pelo método gravimétrico, sendo a amostra aquecida em estufa a $105{ }^{\circ} \mathrm{C}$ durante 3 horas, em cápsula de porcelana, e resfriada em dessecador até atingir a temperatura ambiente (IAL, 2008).

Para análise do teor de minerais totais utilizou-se a técnica de determinação de cinzas através da incineração em mufla. As amostras foram colocadas em cadinhos de porcelana e submetidas ao aquecimento $\left(550\right.$ a $\left.570{ }^{\circ} \mathrm{C}\right)$ por 1 hora. Após resfriamento, foram feitas as pesagens das amostras (IAL, 2008). 
Níveis de sódio foram analisados por fotometria de chama, após digestão úmida das amostras, conforme previamente descrito por SILVA E SILVA (2013).

Os teores totais de lipídeos foram quantificados utilizando como solventes clorofórmio/metanol/água, na proporção de 2: 2: 1,8 v/v (IAL, 2008).

A fim de avaliar a estabilidade química das amostras, foram avaliados os parâmetros de rancidez hidrolítica e oxidativa. A rancidez hidrolítica foi avaliada através do índice de acidez, definido como a quantidade de hidróxido de potássio necessário para neutralizar um grama de amostra. O método de análise se deu por titulação através de soluções álcali-padrão (IAL, 2008). Para determinar a rancidez oxidativa foi realizada a metodologia de TBARS, que consiste na reação do ácido tiobarbitúrico (TBA) com os aldeídos presentes na amostra sob alta temperatura, formando complexos de coloração vermelha. Primeiramente pesou-se o lipídeo obtido pela extração em tubos falcon. Posteriormente acrescentou-se $1 \mathrm{ml}$ de água destilada sob agitação em vórtex por 2 minutos, após foi coletada a fase aquosa e transferida para outro tubo (processo repetido $3 \mathrm{x}$ ). Ao final dessa etapa coletou-se $2,5 \mathrm{ml}$ do extrato aquoso, acrescentou-se 2,5 ml de solução TBA, levando os tubos ao aquecimento em banho-maria à $90{ }^{\circ} \mathrm{C}$ durante por 30 minutos. A leitura espectrofotométrica foi feita após esfriamento das amostras e os resultados foram expressos em mg TBA/kg (PAPASTERGIADIS et al., 2012).

As análises microbiológicas foram realizadas em triplicata conforme metodologia estabelecida na Instrução Normativa No 62/2003 do Mapa (BRASIL, 2003), a partir da dissolução de $25 \pm 0,2 \mathrm{~g}$ de amostra, homogeneizada em $225 \mathrm{ml}$ de água peptonada $0,9 \%$ em equipamento "stomaker".

Para a análise de coliformes foi realizado o Teste Presuntivo partindo da incubação em caldo lauril sulfato triptose (LST), à $37^{\circ} \mathrm{C} \pm 2$ por $48 \pm 2$ horas. Das amostras positivas, foi transferida uma alçada para um tubo contendo Caldo Escherichia coli (EC) e incubado por mais $24 \pm 2$ horas a uma temperatura de $44,5{ }^{\circ} \mathrm{C} \pm 0,1$. De cada tubo de EC que apresentou formação de gás nos tubos de Durham, foi estriada uma alçada no meio de ágar eosina azul de metileno (EMB), após foram submetidas à $35^{\circ} \mathrm{C} \pm 2$ por $24 \pm 2$ horas. Em seguida, foram selecionadas 5 colônias típicas ou atípicas das placas de EMB para serem ativadas em ágar padrão de contagem (PCA) e a partir disso foi realizado o teste IMViC (Indol, Vermelho de Metila, Voges-Proskauer e Citrato). Na leitura dos resultados, o microrganismo E. coli apresentou-se como positivo ou negativo no teste Indol, positivo no Vermelho de Metila e negativo no teste de Vogues Proskauer e de Citrato. Para a análise de Estafilococos coagulase positiva foram utilizados os meios de cultura ágar baird parker enriquecido com emulsão de gema de ovo $10 \mathrm{ml}$ e telurito, caldo infusão cérebro coração e coagulase plasma-EDTA. A inoculação foi feita utilizando as diluições previamente preparadas. As placas semeadas foram incubadas por $44 \pm 2$ horas a $35^{\circ} \mathrm{C} \pm 2$. Das diluições de contagem, foram transferidas de 3 a 5 colônias típicas para tubos com BHI e incubadas a $37^{\circ} \mathrm{C} \pm 2$ por $24 \pm 2$ horas. 
Posteriormente foram feitos os testes da catalase e da coagulase para identificação bioquímica.

A pesquisa de Salmonella $s p$. foi realizada utilizando os meios de culturas pré-enriquecidos de caldo lactosado, e o enriquecimento seletivo foi feito com os caldos Rappaport Vassiliadis (RV) e Tetrationato (TT). O plaqueamento diferencial foi realizado com placas de Bismuto Sulfito (BS), ágar Entérico de Hecktoen (HE) e ágar Xilose Lisina Desoxicolato (XLD). Quando positivos, foram realizados os testes preliminares de confirmação com tubos de ágar Tríplice Açúcar Ferro (TSI) e Lisina Ferro (LIA). Posteriormente foi realizada a confirmação com testes adicionais, quando necessário (BRASIL, 2011).

A pesquisa de Listeria monocytogenes foi realizada com a preparação da amostra adicionada de caldo Fraser Broth seguida de 2 enriquecimentos seletivos, um com o meio cromogênico ALOA (Agar Listeria according to Ottaviani and Agosti) e com o meio OXFORD ou PALCAM. Após o isolamento nos meios seletivos, foram efetuados testes de confirmação e as colônias selecionadas foram inoculadas no meio triptona de soja com extrato de levedura (TSYEA - Triptone Soy Yeast Extract Agar) para posterior identificação bioquímica.

\section{Análise estatística}

A tabulação dos dados foi realizada no programa Microsoft Word Excel. Os resultados foram analisados através do programa Statistical Package for Social Sciences, versão 22.0 (SPSS Inc, Chicago, IL). Os resultados foram expressos em média \pm desvio padrão de três testes independentes para cada análise. As variáveis foram testadas quanto à normalidade pelo teste de Shapiro Wilk. Comparações intra e entre os grupos foram calculadas pela análise de variância ANOVA e pós-teste de Tukey. Para verificar a associação entre as variáveis utilizou-se a análise de correlação de Pearson. Os resultados foram considerados estatisticamente significativos se $\mathrm{p} \leq 0.05$.

\section{RESULTADOS E DISCUSSÃO}

As amostras de queijos foram divididas em categorias conforme o tempo de maturação, sendo: categoria 1 ( $\leq 10$ dias), 2 (entre 20 e 30 dias) e 3 (45 a 60 dias). Para os queijos maturados até 10 dias foi encontrado um teor de umidade cerca de $16 \%$ superior à categoria 2 e $30 \%$ com relação à categoria 3, tendo sido observada diferença estatística significativa para esse parâmetro ( $\mathrm{p}<0.05$; Tabela 1). Sendo assim, os queijos aqui analisados ficaram classificados, conforme a legislação, em queijos de muito alta (1), alta (2) e média umidade (3). 
Tabela 1 - Parâmetros nutricionais e classificação de queijos artesanais Serranos maturados em diferentes tempos.

\begin{tabular}{cccc}
\hline Parâmetros & Categoria 1 & Categoria 2 & Categoria 3 \\
\hline Teor de umidade (\%) & $61,18 \pm 4,13^{\text {a }}$ & $51,12 \pm 0,16^{\mathrm{b}}$ & $42,45 \pm 5,53^{\mathrm{c}}$ \\
\hline Classificação segundo umidade ${ }^{*}$ & 4 & 3 & 2 \\
\hline Teor de minerais totais (\%) & $4,26 \pm 0,06^{\mathrm{a}}$ & $4,22 \pm 0,37^{\mathrm{a}}$ & $4,35 \pm 0,01^{\mathrm{a}}$ \\
\hline Teor de sódio (\%) & $0,735 \pm 0,05^{\mathrm{a}}$ & $0,603 \pm 0,16^{\mathrm{a}}$ & $0,645 \pm 0,01^{\mathrm{a}}$ \\
\hline Teor de lipídeos (\%) & $42,44 \pm 0,91^{\mathrm{b}}$ & $44,31 \pm 6,39^{\mathrm{ab}}$ & $33,82 \pm 1,85^{\mathrm{c}}$ \\
\hline Classificação segundo lipídeos ${ }^{\#}$ & 3 & 3 & 3 \\
\hline
\end{tabular}

Legenda: valores expressos em média \pm desvio padrão. Diferentes letras indicam diferença estatística significativa pela análise de variância ANOVA e pós-teste de Tukey para cada parâmetro avaliado ( $\mathrm{p} \leq 0.05)$. * classificação da umidade (BRASIL, 1996), sendo: baixa (queijo massa dura com até 35,9\%=1; média (queijo massa semidura, entre 36 e 45,9 $\%=2$ ); alta (queijo massa branda, entre 46 e 54,9 \%=3); e muito alta (queijo massa mole, não inferior a $55 \%=4$ ). \#classificação do teor de lipídeos (BRASIL, 1996), sendo: extra-gordos (mínimo de 60 \% = 1); gordos (entre 45 e 59,9 $\%=2$ ); semi-gordos (entre 25 e 44,9\%=3; magros (entre 10 e 24,9\%=4) e desnatados (inferior à $10 \%=5$ ).

A umidade é um parâmetro muito importante a ser analisado, essa não representa apenas a estabilidade, mas também a qualidade dos queijos. Algumas hipóteses têm sido levantadas para explicar as diferenças no teor de umidade desse alimento, como por exemplo, a época do ano. Oliveira et al. (2012) encontrou menor teor de umidade nos queijos produzidos no verão e atribuiu esse achado às condições de alta temperatura e baixa umidade relativa do ar. No mesmo estudo, os autores encontraram uma porcentagem de umidade entre 47,8 e 61,6 \%, classificando os queijos como alta e muito alta umidade, ficando muito próximo dos valores encontrados no presente estudo. Por outro lado, os dados encontrados pelas autoras SILVA E SILVA (2013) mostraram índices de umidade de 36 a 55 \% em queijos coloniais sem data definida de maturação. SILVA et al. (2011) analisaram 24 amostras de queijos Minas coloniais frescos e maturados por período não determinado e observaram uma porcentagem maior de umidade nos queijos frescos com média de $47 \%$, enquanto, que os queijos maturados apresentaram um valor médio de $33 \%$. Conforme os autores, $67 \%$ dos queijos frescos estavam em desacordo com a legislação (IMA, 2004) por apresentarem umidade superior à $46 \%$. Resultados semelhantes foram encontrados por FERNANDES et al. (2013). Os autores destacaram que a umidade é um parâmetro necessário para mensurar o tempo de maturação dos queijos. Desse modo, salienta-se que os queijos vêm sendo comercializados antes que os níveis de umidade alcancem o determinado pela legislação.

Os queijos apresentam alto valor nutricional por conterem, além de macronutrientes, micronutrientes como cálcio, fósforo, cloro e sódio. Esses ajudam na coagulação do leite, contribuindo para a consistência do queijo (PERRY, 2004). No presente estudo, o tempo de maturação não interferiu na composição mineral das amostras, as quais apresentaram um perfil similar de minerais e sódio. Embora não tenha sido encontrada uma diferença estatística significativa, as amostras da categoria 1 apresentaram cerca de 1,2\% maior teor de sódio do que as categorias 2 e $3(p=0,424$; Tabela 1). No estudo de SILVA E SILVA (2013) foi demonstrada uma variação de 3,06 a 6,99 \% no total de minerais de queijos maturados por um período não definido. Os autores atribuíram esse achado a falta 
de padronização durante o processo de fabricação, especialmente no momento da salga, quando é feita a adição de quantidades aleatórias de cloreto de sódio. Segundo OLIVEIRA (2011), o percentual de minerais para queijos in natura deve estar entre 1 e $6 \%$. LOUVATEL E DEGENHARDT (2015) analisaram queijos coloniais de 6 a 13 dias de maturação e encontraram um teor de 2,64 a 6,07\%, estando de acordo com o reportado por OLIVEIRA (2011) e confirmado por FIGUEREDO (2006), os quais descreveram teores entre 3,95 e 3,99 \% nos queijos Marajó. Os autores observaram também que a quantidade de sódio ideal para melhorar a palatabilidade do produto seria em torno de 2,5\%. $\mathrm{Na}$ literatura observa-se que não há consenso em relação ao teor de sódio adicionado. Por exemplo, a quantidade de sódio recomendada por FIGUEREDO (2006) é de 1,5\%. O estudo de SILVEIRA JUNIOR (2012), que analisou 6 marcas diferentes de queijos coloniais maturados por 30 dias, apresentou teores de sódio entre 0,25 e $0,58 \%$. O sódio é adicionado diretamente no leite, na massa, na salga à seca, na superfície do produto ou ainda por imersão na salmoura. Tem sido mostrado que concentrações de sódio abaixo de $2 \%$ podem contribuir para uma maior susceptibilidade à contaminação, já que o sal regula as atividades enzimáticas em diversos níveis afetando o crescimento de microrganismos (FREITAS FILHO E FERREIRA, 2011).

A legislação brasileira através da Portaria no 146 (BRASIL, 1996) classifica os queijos quanto ao teor de gordura em magros: $<10$ a 24,9 \%; semi-gordos 25 a 44,9\%; gordos 45 a 54,9 \% e extra-gordos ou duplo creme $\geq 60 \%$. No presente estudo, considerando os percentuais médios de lipídeos encontrados, os mesmos podem ser classificados como produtos semi-gordos (Tabela 1). Dentre as 3 categorias que foram analisadas, a categoria 3 diferiu significativamente da 1 e 2 , apresentando um conteúdo lipídico $22 \%$ inferior às demais. Em contrapartida, os queijos analisados por OLIVEIRA et al. (2013) apresentam baixos teores de lipídeos (23,68 à $28 \%$ ), com um diferencial entre as estações do ano, onde no verão há uma maior concentração de lipídeos devido a melhor qualidade da alimentação dos animais. Em estudo realizado por LOUVATEL E DEGENHARDT (2015) foi encontrado um teor de 14,77 e 32,28 \% em queijos artesanais maturados de 6 a 14 dias. Segundo o mesmo estudo, as modificações do teor de gordura do queijo podem ser explicadas pela dieta ofertada aos animais, além da influência genética.

O queijo é um produto muito manipulado, motivo que leva a maior possibilidade de contaminação biológica. No presente estudo, $100 \%$ das amostras coletadas apresentaram contagem de microrganismos acima do definido pela legislação (Tabela 2). Os coliformes a $45{ }^{\circ} \mathrm{C} / \mathrm{g}$ podem estar presentes até $10^{3} \mathrm{UFC} / \mathrm{g}$, no entanto $100 \%$ das amostras apresentaram índices acima dos estabelecidos na legislação ( $>1100 \mathrm{NMP} / \mathrm{g})$, e inviabilizam o consumo desse alimento. Já para $E$. coli, as pesquisas apontaram a presença em 53,84 \% das amostras. Observou-se ainda que as amostras coletadas apresentavam-se estufadas e com muitas olhaduras consequentemente causadas por microrganismos do grupo coliformes que fermentam lactose formando gás (dados não mostrados). O estufamento 
torna-se visível quando a contagem de microrganismos atinge valores de aproximadamente 100 a 400 coliformes/g comprometendo o sabor e aparência do produto (McSWEENEY, 2007).

Tabela 2 - Contagem de microrganismos pesquisados no queijo Serrano durante o período da maturação.

\begin{tabular}{ccccc}
\hline Microrganismos & Categoria 1 & Categoria 2 & Categoria 3 & RDC 12/2001 \\
Coliformes termotolerantes (NMP/g) & $>1100$ & $>1100$ & $>1100$ & $5 \times 10^{3}$ \\
\hline Estafilococcus coagulase positiva (UFC/g) & $1,6 \times 10^{5}$ & $2,7 \times 10^{5}$ & $1,6 \times 10^{4}$ & $10^{3}$ \\
\hline Salmonella spp. $/ 25 \mathrm{~g}$ & Presente & Presente/Ausente & Ausente & Ausente \\
\hline Listeria monocytogenes/25g & Ausente & Ausente & Ausente & Ausente \\
\hline
\end{tabular}

A legislação preconiza que os Estafilococos coagulase positiva/g não ultrapassem $10^{3} \mathrm{UFC} / \mathrm{g}$, no entanto, $100 \%$ das amostras estavam com valores acima dos exigidos, porém houve uma redução na concentração desse microrganismo com o processo de maturação. Essa redução foi cerca de 10 vezes na categoria 3 em comparação a 1 (Tabela 2). Já para a salmonela, observou-se que a categoria 1 foi positiva para o microrganismo e a 3, ausente. Adicionalmente, conforme a legislação, além da salmonela, outro microrganismo que deve estar ausente nesse alimento é a Listeria monocytogenes. Em todas as amostras analisadas não foi detectada a presença desse patógeno, porém foi identificada a presença de Listeria spp. Esses achados podem ser atribuídos às condições sanitárias, não só na hora de comercializar, mas também durante a produção, além da inocuidade das matérias-primas, como previamente observado (PERRY, 2004).

O período mínimo de maturação do queijo Serrano é de 60 dias, contudo, um período menor pode ser aceito através de estudos que comprovem a qualidade e a inocuidade do mesmo (CRUZ E MENASHE, 2014; FREITAS, 2015; SANTA CATARINA, 2017). No presente estudo, as análises realizadas mostraram que mesmo respeitando o período mínimo de maturação conforme a exigência legal, este alimento não estaria apto para consumo. Estudos prévios encontraram presença de microrganismos em diferentes amostras de queijos artesanais (SANTANA et al., 2008; OLIVEIRA, 2011), corroborando os dados aqui encontrados.

A presença de microrganismos pode causar alterações físicas e químicas no queijo (ZAFFARI et al., 2007). A degradação da gordura, tanto pela ação dos microrganismos quanto por reações não enzimáticas, pode causar rancidez (SOBRAL et al., 2017). Nesse sentido, marcadores de rancidez hidrolítica e oxidativa foram avaliados e estão apresentados na Figura 1.

O nível de acidez foi maior nas amostras da categoria 1, seguidas das categorias 2 e 3 , indicando um efeito tempo dependente. Os queijos da categoria 3 apresentaram valores inferiores em cerca de 2,8 vezes quando comparados aos da 1 . Com relação à rancidez oxidativa, se pôde evidenciar que as categorias 1 e 2 exibiram resultados semelhantes, ao mesmo tempo em que foram superiores em cerca de $60 \%$ aos queijos da categoria 3 . Assim pode-se observar que os queijos menos maturados tendem a ter mais acidez e sofrer maior incidência de rancidez oxidativa. 
Figura 1 - Grau de rancidez das amostras de queijos agrupadas de acordo com o tempo de maturação:

(A) marcador de rancidez hidrolítica; (B) marcador de rancidez oxidativa.

A)

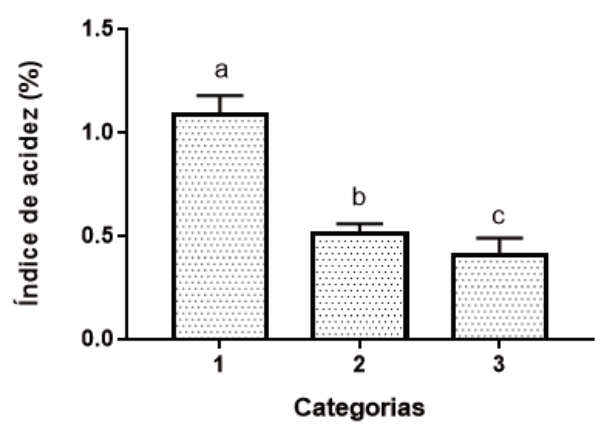

B)

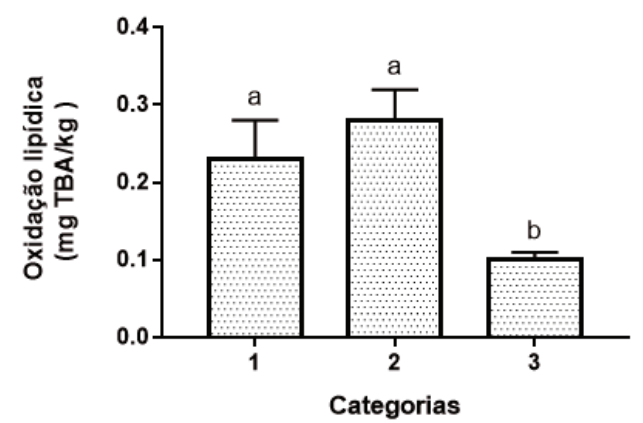

Legenda: Categoria 1 (< à 10 dias), categoria 2 (entre 20 e 30 dias) e categoria 3 (45 à 60 dias). Diferentes letras indicam diferença estatística de acordo com a análise de variância ANOVA e pós-teste de Tukey $(\mathrm{p} \leq 0.05)$.

Estudos têm demonstrado que quanto maior o índice de umidade dos queijos, maior a sua instabilidade (SOBRAL et al., 2017). Um dos processos químicos que ocorre nesse sentido é a ação das lipases, que clivam as ligações ésteres dos triacilgliceróis, liberando ácidos graxos e glicerol. Assim, um aumento na liberação dos ácidos graxos pela ação enzimática aumenta o índice de acidez, o qual por sua vez pode vir acompanhado por alteração na constituição destes, como decorrência do processo de rancidez oxidativa. Muitos ácidos graxos liberados pela ação enzimática podem conter ligações duplas em sua composição, favorecendo assim o processo de oxidação por espécies reativas de oxigênio. Embora sejam importantes para a manutenção do valor nutricional, esses lipídeos podem ser facilmente oxidados o que pode levar à decomposição de ácidos graxos essenciais (linoleico, linolênico e araquidônico) e vitaminas lipossolúveis (A, D, E, K), além de gerar compostos poliméricos potencialmente tóxicos (BARROS, 2012; REIS, 2013). Dentre esses compostos, os peróxidos lipídicos são conhecidos por serem os primeiros metabólitos gerados na oxidação. São instáveis e se decompõem em produtos intermediários secundários, como aldeídos, acetonas e dienos (BARROS, 2012). Esses são produtos finais da peroxidação lipídica que podem ser percebidos sensorialmente em concentrações em torno de 0,5 à 2,0 mg TBA/kg (O’NEILL et al., 1998). Segundo TERRA et al. (2006), valores de TBA superiores a $1,59 \mathrm{mg} / \mathrm{kg}$ de amostra indicam um risco potencial à saúde do consumidor. No presente estudo nenhuma das amostras apresentou valores superiores a este índice.

Neste estudo foram encontradas correlações que explicitam a ligação entre os fenômenos de rancificação hidrolítica e oxidativa com os parâmetros de umidade, teor de minerais e sódio e conteúdo de lipídeos dos queijos (Tabela 3). Encontraram-se correlações positivas de média intensidade entre umidade e rancidez hidrolítica $(r=0.510 ; p=0.043)$, sódio e minerais $(r=0,673 ; p=0,004)$ e entre lipídeos e rancidez oxidativa $(r=0,614 ; \mathrm{p}=0,011)$. Esses achados demonstram que quanto maior o teor de umidade e de lipídeos maior é a rancidez hidrolítica e oxidativa respectivamente, ou seja, a rancidez é menor nos queijos mais maturados e magros. 
Tabela 3 - Coeficiente de correlação (r) de Pearson entre os parâmetros avaliados nas amostras de queijos da Serra Gaúcha.

\begin{tabular}{ccccccc}
\hline & Umidade & Minerais & Sódio & Lipídeos & $\begin{array}{c}\text { Rancidez } \\
\text { hidrolítica }\end{array}$ & $\begin{array}{c}\text { Rancidez } \\
\text { oxidativa }\end{array}$ \\
\hline \multirow{2}{*}{ Umidade } & - & $\mathrm{r}=-0,214$ & $\mathrm{r}=0,308$ & $\mathrm{r}=0,277$ & $\mathrm{r}=0,510^{*}$ & $\mathrm{r}=0,194$ \\
& & $\mathrm{p}=0,427$ & $\mathrm{p}=0,245$ & $\mathrm{p}=0,300$ & $\mathrm{p}=0,043$ & $\mathrm{p}=0,472$ \\
Minerais & $\mathrm{r}=-0,214$ & & $\mathrm{r}=0,673^{*}$ & $\mathrm{r}=-0,314$ & $\mathrm{r}=0,026$ & $\mathrm{r}=-0,101$ \\
& $\mathrm{p}=0,427$ & - & $\mathrm{p}=0,004$ & $\mathrm{p}=0,236$ & $\mathrm{p}=0,925$ & $\mathrm{p}=0,709$ \\
Sódio & $\mathrm{r}=0,308$ & $\mathrm{r}=0,673 *$ & & $\mathrm{r}=-0,166$ & $\mathrm{r}=0,394$ & $\mathrm{r}=-0,032$ \\
& $\mathrm{p}=0,245$ & $\mathrm{p}=0,004$ & - & $\mathrm{p}=0,538$ & $\mathrm{p}=0,131$ & $\mathrm{p}=0,907$ \\
Lipideos & $\mathrm{r}=0,277$ & $\mathrm{r}=-0,314$ & $\mathrm{r}=-0,166$ & & $\mathrm{r}=0,043$ & $\mathrm{r}=0,614 *$ \\
& $\mathrm{p}=0,300$ & $\mathrm{p}=0,236$ & $\mathrm{p}=0,538$ & & $\mathrm{p}=0,875$ & $\mathrm{p}=0,011$ \\
Rancidez & $\mathrm{r}=0,510^{*}$ & $\mathrm{r}=0,026$ & $\mathrm{r}=0,394$ & $\mathrm{r}=0,043$ & & $\mathrm{r}=-0,047$ \\
hidrolitica & $\mathrm{p}=0,043$ & $\mathrm{p}=0,925$ & $\mathrm{p}=0,131$ & $\mathrm{p}=0,875$ & - & $\mathrm{p}=0,862$ \\
Rancidez & $\mathrm{r}=0,194$ & $\mathrm{r}=-0,101$ & $\mathrm{r}=-0,032$ & $\mathrm{r}=0,614 *$ & $\mathrm{r}=-0,047$ & \\
oxidativa & $\mathrm{p}=0,472$ & $\mathrm{p}=0,709$ & $\mathrm{p}=0,907$ & $\mathrm{p}=0,011$ & $\mathrm{p}=0,862$ & - \\
\hline
\end{tabular}

Legenda: significância estatística $(\mathrm{p} \leq 0.05)$.

\section{CONCLUSÃO}

No presente estudo foi encontrada contaminação microbiológica em 100 \% das amostras avaliadas. A presença dos microrganismos parece ter contribuído para a geração de metabólitos secundários, substratos da rancidez hidrolítica e oxidativa, como foi evidenciado pelas análises de correlação. A ocorrência de tais fenômenos químicos e biológicos é responsável pelas alterações indesejáveis nas características organolépticas e no valor nutricional dos queijos analisados.

Tendo em vista a importância do queijo artesanal Serrano como fonte de renda para os pequenos produtores e por ser um produto muito apreciado pelo consumidor, destaca-se a necessidade de uma maior adequação às normas da legislação que busquem valorizar ainda mais esse alimento. A criação de cooperativas, por exemplo, pode ser uma alternativa para capacitar produtores nas questões higiênico-sanitárias e no processo de fabricação e comercialização do queijo artesanal da Serra Gaúcha, garantindo assim um produto seguro e inócuo para o consumidor final.

\section{REFERÊNCIAS}

ASSOCIAÇÃO BRASILEIRA DAS INDÚSTRIAS DE QUEIJO (ABIQ). Os queijos no Brasil. Disponível em: https://www.abiq.com.br/index.asp. Acesso em: 20 jun. 2019.

BARROS, E. A. Estudo de lipoxigenases em extrato hidrossolúvel de soja (Glycine max (L.) MERR.) submetido a diferentes tratamentos. Botucatu, SP Agosto, 2012. Disponível em: https:// bit.ly/3hPTzwP. Acesso em: 10 out. 2018. 
BRASIL. Ministério da Agricultura, Pecuária e Abastecimento. Portaria n. 146. Aprova os Regulamentos Técnicos de Identidade e Qualidade dos Produtos Lácteos, Diário Oficial da União, Brasília, DF, 7 de março de 1996.

BRASIL. Ministério da Agricultura, Pecuária e Abastecimento. Instrução Normativa nº 62, de 26 de agosto de 2003. Oficializa os métodos analíticos oficiais para análises microbiológicas para controle de produtos de origem animal e água. Diário Oficial da União, Brasília, DF, 18 set. Seção 1, p. 14. 2003.

BRASIL. Ministério da Saúde. Secretaria de Vigilância em Saúde. Manual técnico de diagnóstico laboratorial de Salmonella spp.: diagnóstico laboratorial do gênero Salmonella / Ministério da Saúde. Secretaria de Vigilância em Saúde, Fundação Oswaldo Cruz. Laboratório de Referência Nacional de Enteroinfecções Bacterianas, Instituto Adolfo Lutz. Brasília, DF. 60 p.: il, 2011.

CRUZ FT; MENASHE R. O debate em torno de queijos feitos de leite cru: entre aspectos normativos e a valorização da produção tradicional. Vigilância Sanitária em Debate: Sociedade, Ciência \& Tecnologia, v. 2, n. 04, p. 34-42, 2014.

FERNANDES, R.V. B. et al. Avaliação físico-química, microbiológica e microscópica do queijo artesanal comercializado em rio Paranaíba-MG. Revista do Instituto de Laticínios Cândido Tostes, v. 66, n. 382, p. 21-26, 2013.

FIGUEREDO, E. L. Elaboração e caracterização do "Queijo Marajó", tipo creme, de leite de búfala, visando sia padronização. Dissertação (Mestrado em Ciência Animal). Universidade Federal do Pará. Belém, 2006. Disponível em: https://bit.ly/2V3mPGy. Acesso em: 30 maio 2019.

FILHO, J. de F.; FERREIRA, W. L. Avaliação dos parâmetros físico-químicos do queijo coalho comercializado na cidade dos Barreiros-PE. In: Congresso Brasileiro de Química, 48, 2008, Rio de Janeiro. Anais do $\mathbf{4 8}^{\circ}$ Congresso Brasileiro de Química, Rio de Janeiro: SBQ, 2011.

FREITAS, CA. Queijo com história e identidade. Revista Agropecuária Catarinense, v. 28, n. 1, p. 19-24, 2015.

INSTITUTO ADOLFO LUTZ (IAL). Método físico-químicos para análise de alimentos. São Paulo: Instituto Adolfo Lutz, 1020 p, 2008. 
INSTITUTO MINEIRO DE AGROPECUÁRIA (IMA). Portaria n⿳ 694, de 17 de novembro de 2004. Identifica a microrregião da Canastra como produtora do queijo Minas artesanal. Belo Horizonte, 2004. Disponível em: https://bit.ly/2YOTZuC. Acesso em: 06 maio 2019.

LOUVATEL, K.; DEGENHARDT, R. Caracterização bromatológica de queijos coloniais produzidos no distrito de Santa Lúcia, município de Ouro, SC. Jornada Integrada em Biologia, p. 37-46, 2015. Disponível em: https://bit.ly/3eiI5iT. Acesso em: 05 maio 2019.

McSWEENEY, 2007 et al. Cheese problems solved. CRC Press: Boca Raton, Boston, New York, Washington, 425 p, 2007.

O’NEILL, L.M. et al. Comparison of effects of dietary olive oil, tallow and vitamin E on the quality of broiler meat products. British Poultry Science, v. 39, p. 365-371, 1998.

OLIVEIRA, D. F. Estudo da interferência da sazonalidade na composição centesimal e qualidade microbiológica de queijos coloniais. 2011. $40 \mathrm{f}$. Trabalho de conclusão de curso (Tecnologia em alimentos). Universidade Tecnológica Federal do Paraná. Francisco Beltrão, 2011. Disponível em: https://bit.ly/2YdUhMg. Acesso em: 31 maio 2019.

OLIVEIRA, D. F. et al. Sazonalidade como fator interferente na composição físico-química e avaliação microbiológica de queijos coloniais. Arquivo Brasileiro de Medicina Veterinária e Zootecnia, v. 64, n. 2, p. 521-523, 2012.

OLIVEIRA, D. F. et al. Caracterização físico-química de queijos minas artesanal produzidos em diferentes microrregiões de Minas Gerais. Revista Brasileira de Economia Doméstica, v. 24, n. 2 , p. 185-196, 2013.

PAPASTERGIADIS, A. et al. Malondialdehyde measurement in oxidized foods: evaluation of the spectrophotometric thiobarbituric acid reactive substances (TBARS) test in various foods. Agric. Food Chem, v. 60, n. 38, p. 9589-94, 2012.

PEREIRA, B.P. et al. Implications of the quality of the production process artisan cheese serrano. Revista Eletrônica em Gestão, Educação e Tecnologia Ambiental, v. 18, p. 116-126, 2014.

PERRY, K. S. P. Queijos: aspectos químicos, bioquímicos e microbiológicos. Química Nova, v. 27, n. 2, p. 293-300. 2004. 
REIS, R. C. Influência da dieta, do uso de antioxidantes e da conservação por congelamento na oxidação lipídica da carne bovina. Goiânia, Set/2013. Disponível em: https://bit.ly/2Nc48vV. Acesso em: 04 out. 2018.

RIO GRANDE DO SUL. Lei $\mathbf{n}^{\mathbf{0}}$ 14.973, de 29 de dezembro de 2016. Dispõe sobre a produção e a comercialização do queijo artesanal serrano no Estado do Rio Grande do Sul. Diário Oficial Eletrônico do Rio Grande do Sul, RS. 2016.

SANTA CATARINA. Decreto n 1.238, de 19 de julho de 2017. Regulamenta a lei 17.003, de 2016, que dispõe sobre a produção e comercialização do queijo artesanal serrano no estado de Santa Catarina. Diário Oficial Eletrônico de Santa Catarina, SC. 2017.

SANTANA, R.F. et al. Qualidade microbiana do queijo de coalho comercializado em Aracaju, SE. Arq. Bras. Med. Veterinario. Zootec, v. 60, n. 6, p. 1517-1522, 2008.

SILVA, F. DA; SILVA, G. D. A. Análise microbiológica e físico-química de queijos coloniais com e sem inspeção, comercializados na microrregião de Francisco Beltrão-PR. 2013. 58 F. Trabalho de conclusão de curso (graduação) Universidade Tecnológica Federal Paraná, Francisco Beltrão, 2013. Disponível em: https://bit.ly/3dcWr3f. Acesso em: 10 set. 2019.

SILVA, J. G; et al. Características físico-químicas do queijo Minas artesanal da Canastra. Revista do Instituto de Laticínios Cândido Tostes, v. 66, n. 380, p. 16-22, 2011.

SILVEIRA JUNIOR, J. F. et al. Caracterização físico-química de queijos coloniais produzidos em diferentes épocas do ano. Revista do Instituto de Laticínios Cândido Tostes, v. 67, p. 67-80, 2012.

SOBRAL, D. et al. Principais defeitos em queijo minas artesanais: uma revisão. Revista do Instituto Laticínios Cândido Tostes, v. 72, 2, p. 108-120, 2017.

TABELA BRASILEIRA DE COMPOSIÇÃO DE ALIMENTOS (TACO). 4. ed. rev. e ampl. Campinas: NEPA - UNICAMP, 161 p., 2011.

TERRA, N. N. et al. Valores de nitrito e TBARS durante o processamento e armazenamento da paleta suína curada, maturada e fermentada. Revista Ciência Rural, v. 36, n. 3, p. 965-970, 2006.

ZAFFARI, C. B. et al. Qualidade bacteriológica de queijos artesanais comercializados em estradas do litoral norte do Rio Grande do Sul, Brasil. Revista Ciência Rural, v. 37, n. 3, p. 862-867, 2007. 
